\title{
ESTUDO DO EFEITO DA TERAPIA FOTODINÂMICA ANTIMICROBIANA SOBRE A VIABILIDADE DO BIOFILME PRODUZIDO POR Candida albicans
}

\author{
Ana Paula Pinto ${ }^{1}$ \\ Isabela Bueno Rosseti ${ }^{2}$ \\ Maricilia Silva Costa ${ }^{3}$
}

Resumo: A C. albicans é um fungo comensal e oportunista, que em casos de imunossupressão pode causar infecções e levar o indivíduo à morte. O biofilme produzido por C. albicans apresenta resistência a vários antifúngicos, pois é formado por uma matriz extracelular que dificulta a difusão dos fármacos. $A$ Terapia Fotodinâmica Antimicrobiana (TFA) é uma terapia que combina uma fonte de luz visível, um agente fotossensível (não tóxico) e oxigênio. Esta interação promove a produção de espécies reativas de oxigênio (ERO's), que alteram a permeabilidade da membrana celular e podem levar à morte celular de microrganismos. Foi realizada a TFA em biofilmes produzidos por C. albicans em diferentes fases de desenvolvimento. A fonte de luz utilizada foi um Light Emitting Diode (LED) (630nm) e o agente fotossenssível utilizado foi o Azul de Toluidina (AT). Os resultados demonstraram que tanto sobre a formação quanto sobre o biofilme produzido por C. albicans a TFA foi capaz de reduzir a viabilidade celular e alterar a morfologia, diminuindo a quantidade do número de células e de filamentos. Assim, a TFA demonstra ser uma potencial terapia antifúngica.

Palavras-chave: Candida albicans; Biofilme; Terapia Fotodinâmica Antimicrobiana; Azul de Toluidina.

\footnotetext{
${ }^{1}$ Discente em Fisioterapia, Instituto de Pesquisa e Desenvolvimento (IP\&D) - UNIVAP, Laboratório de Bioquímica Aplicada à Engenharia Biomédica, Brasil. E-mail: apaula@outlook.com.br.

2 Doutora em Engenharia Biomédica, Instituto de Pesquisa e Desenvolvimento (IP\&D) - UNIVAP, Laboratório de Bioquímica Aplicada à Engenharia Biomédica, Brasil. E-mail: isabelabros@hotmail.com.

3 Profa. Doutora, Instituto de Pesquisa e Desenvolvimento (IP\&D) - UNIVAP, Laboratório de Bioquímica Aplicada à Engenharia Biomédica, Brasil. E-mail: mscosta@univap.br.
} 